\title{
Rekayasa Teknik Merubah Nama Kartu Grafis AMD Radeon Menggunakan Notepad Pada Sistem Operasi Windows 10
}

\author{
Ary Budi Warsito ${ }^{1}$ \\ Khalid Al Fikri ${ }^{2}$
}

\begin{abstract}
Alumni Magister Ilmu Komputer Universitas Budi Luhur Jakarta ${ }^{1}$, Mahasiswa STMIK Raharja ${ }^{2}$ Email: arybudiwarsito@raharja.info ${ }^{1}$; khalid.alfikri@raharja.info ${ }^{2}$
\end{abstract}

\begin{abstract}
ABSTRAK
Nama Kartu grafis merupakan bentuk informasi sebuah perangkat komputer maupun perangkat laptop yang sangat penting saat ini, selain fungsinya sangat di sukai hampir di seтua kalangan, perangkat komputer yang satu ini tidak bisa jauh dari pasangannya yaitu sebuah prosesor, tidak ada kartu grafis maka prosesor tidak akan menunjukan fungsinya dengan maksimal. Sebut saja salah satu brand kartu grafis terkenal, yaitu AMD (Advanced Micro Device). Namun penamaan kartu grafis yang diberikan AMD lewat driver masih kurang jelas dan akurat, dikarenakan developer yang mengelola divisi driver AMD ini masih malas merubah nama produk kartu grafisnya satu per satu setiap brand, oleh karena itu maka penulis akan membuat Rekayasa teknik merubah nama kartu grafis AMD Radeon Menggunakan Notepad pada sistem operasi windows 10, sehingga dengan ini user atau pengguna kartu grafis AMD Radeon akan bisa lebih memahami secara mendalam mengapa kartu grafis ini namanya tidak sesuai.
\end{abstract}

Kata Kunci: Kartu Grafis, AMD Radeon, Notepad

\begin{abstract}
The name of the graphics card is a form of information devices and laptop computers are very important at this time, in addition to its functions very preferred in almost all circles of computer devices, this one could not be furtherfrom his partner a processor, no graphics card then the processor will not indicate it functions optimally. Call it one of the brand famous, i.e. graphics card AMD (Advanced Micro Device). But the naming of the given graphics card AMD passing drivers still less clear and accurate, due to the developer who manages the Division drivers AMD is still lazy graphics card product name change one by one each brand, therefore then the author would make engineering change name AMD Radeon graphics card using Notepad on a windows operating system 10, so with this user or users of the AMD Radeon graphics card will be able to understand more deeply why this graphics card name is not appropriate.
\end{abstract}

Keywords: Graphics Card, AMD Radeon, Notepad

\section{PENDAHULUAN}

Perkembangan teknologi yang terus meningkat dengan cepat, mempengaruhi laju kebutuhan manusia yang tidak jauh dari suatu kebutuhan perangkat keras, terlebih 
untuk end user atau pun suatu komunitas. Kebutuhan suatu hiburan atau pun kebutuhan para professional terus mengalir dan jumlahnya semakin lama semakin meningkat seiring dengan jumlahnya permintaan, serta jumlah perangkat yang semakin banyak. Seperti halnya salah satu perangkat komputer terpenting yaitu kartu grafis, end user atau pemakai ingin sekali tahu nama kartu grafisnya dengan jelas sehingga mereka bisa lebih mudah untuk mengakses suatu aplikasi dengan nama kartu grafis yang begitu jelas. Seperti pabrikan hardware terkemuka misalnya yaitu AMD (Advanced Micro Device) yang sudah biasa memproduksi berbagai macam komponen seperti prosesor, ram, serta kartu grafis yang biasa kita sebut VGA (Video Graphic Adapter) yang namanya biasa disebut AMD Radeon Graphic.

Berbekal dari pengalaman yang sudah berkali-kali upgrade driver VGA setiap bulan, sering sekali penamaan kartu grafisnya tidak akurat atau namanya tidak sesuai dengan nama produknya, penulis melakukan berbagai macam cara untuk bisa merubah nama kartu grafis ini hingga semua sistem dapat membacanya dengan benar, mulai dari memodifikasi registry hingga operasi sistem yang sering mengalami Blue screen off death (Bsod). Oleh karena itu pada akhirnya mulai tertarik untuk meneliti dan mempelajari bagaimana sebuah kartu grafis bisa terbaca oleh sistem saat pertama kali.

Diawali dengan terbongkarnya sebuah file setup informasi (setup information) yang dibuat dengan Notepad, penulis melakukan beberapa penyesuaian dengan Notepad dan Startup Windows, mulai dari teknik editing text dari Notepad, hingga teknik men disable salah satu fitur yang ada di startup windows, Dan pada akhirnya dipaparkan secara terbuka pada penulisan yang berjudul "Rekayasa Teknik Merubah Nama Kartu Grafis Amd Radeon Menggunakan Notepad Pada Sistem Operasi Windows 10.

Dari paparan diatas tentunya kita bertanya akan adanya beberapa permasalahan yang harus dipecahkan, Bagaimana mungkin sebuah kartu grafis yang namanya sudah permanen dari pabrikan bisa di rubah? Adakah program aplikasi yang mampu merubah nama kartu grafis dengan mudah? Mampukah sebuah notepad bisa merubah nama kartu grafis kususnya produk AMD Radeon dengan teknik text editing? Bagaimanakah rekayasa teknik merubah nama kartu grafis AMD Radeon dengan menggunakan Notepad dan men-disable Startup windows?

Walaupun akan membahas tentang rekayasa teknik merubah text editor pada Notepad dan Men-disable salah satu startup di windows 10, penulis membatasi pembahasan hanya pada teknik merubah text editor di notepad dan Men-disable salah satu startup di windows 10, tidak sampai pada teknik membeli produk baru supaya nama VGA berubah seutuhnya, hal ini dimaksudkan karena tulisan ini untuk menambah wawasan dalam merubah nama produk agar terlihat jadi lebih baik kepada end user, dengan harapan dapat memberikan sesuatu yang positif dan bukan digunakan untuk tujuan negatif. 


\section{PERMASALAHAN}

Mengubah nama kartu grafis memiki banyak kegunaan terlebih untuk mengetahui informasi sebuah perangkat dekstop maupun laptop, mengubah nama kartu grafis juga memungkinkan suatu sistem dapat membaca perangkat dengan jelas dan akurat, hal ini karena banyaknya sebuah software yang dapat membaca semua perangkat sistem keseluruhan. Jika sebuah notepad saja bisa mengubah nama sebuah perangkat kususnya kartu grafis AMD Radeon tentunya ini akan menimbulkan spekulasi, tentu saja pengguna atau user mengharapkan lebih kepada perangkat yang mereka pakai, seperti halnya performa dari kartu grafis tersebut, padahal sebuah performa dari kartu grafis dapat dilihat dari nama dan seri kartu grafinya, seperti achitecture dan jumlah Transistor misalnya. Architecture di sebuah kartu grafis sangatlah penting untuk menyusun sebuah Transistor yang padat dan jumlahnya besar, hal ini juga berlaku untuk konsumsi daya dari kartu grafis tersebut, kartu grafis yang baik adalah yang mampu memberikan performa terbaik namun efisien konsumsi dayanya.

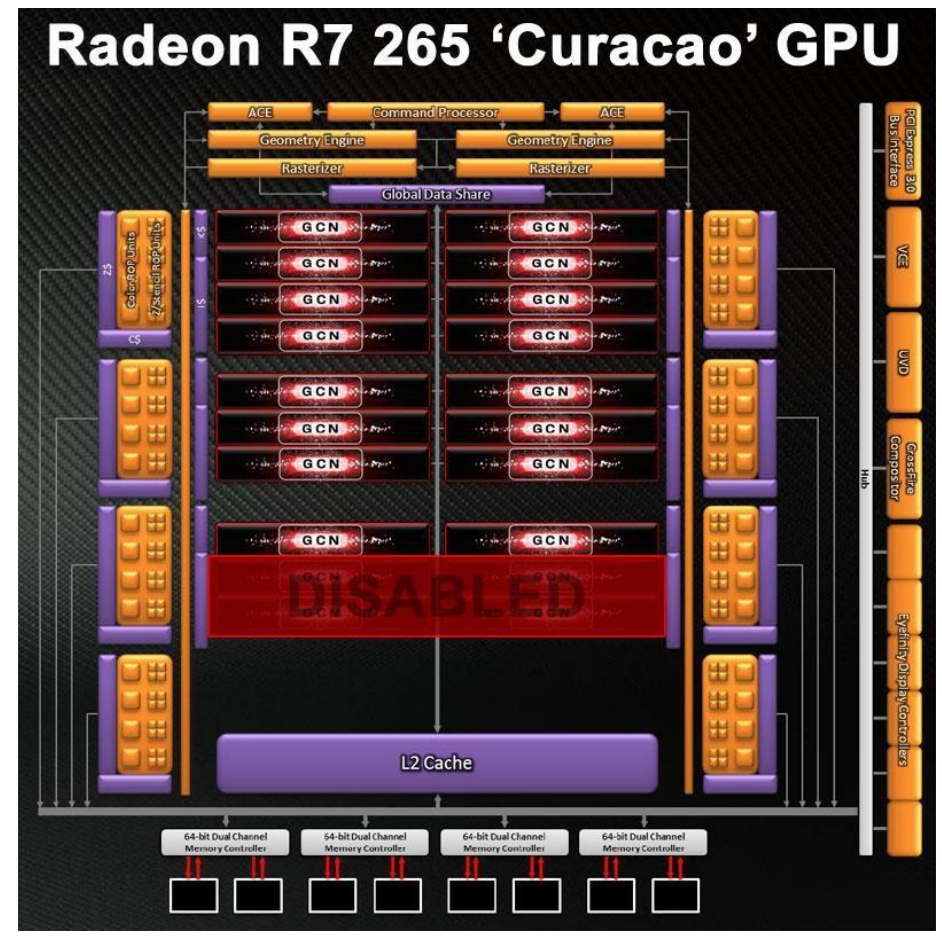

Gambar 1. GCN Arsitektur

Gambar diatas adalah sebuah susunan CU (Compute Unit) atau core pada kartu grafis AMD Radoen R7 265, CU ini disusun dengan susunan arsitektur yang bernama GCN (Graphic Core Next) engine, jumlah CU ini adalah 16, yang artinya kartu grafis ini memiliki 16 core GPU, hal inilah yang bisa menjadi tolak ukur sebuah performa kartu grafis apapun seri dan nama brand kartu grafis-nya. Akan tetapi arsitektur dan jumlah core GPU bukanlah satu-satunya tolak ukur menentukan performa, masih ada Bandwith yang dihasilkan dari Bus dan clock speed memory. 


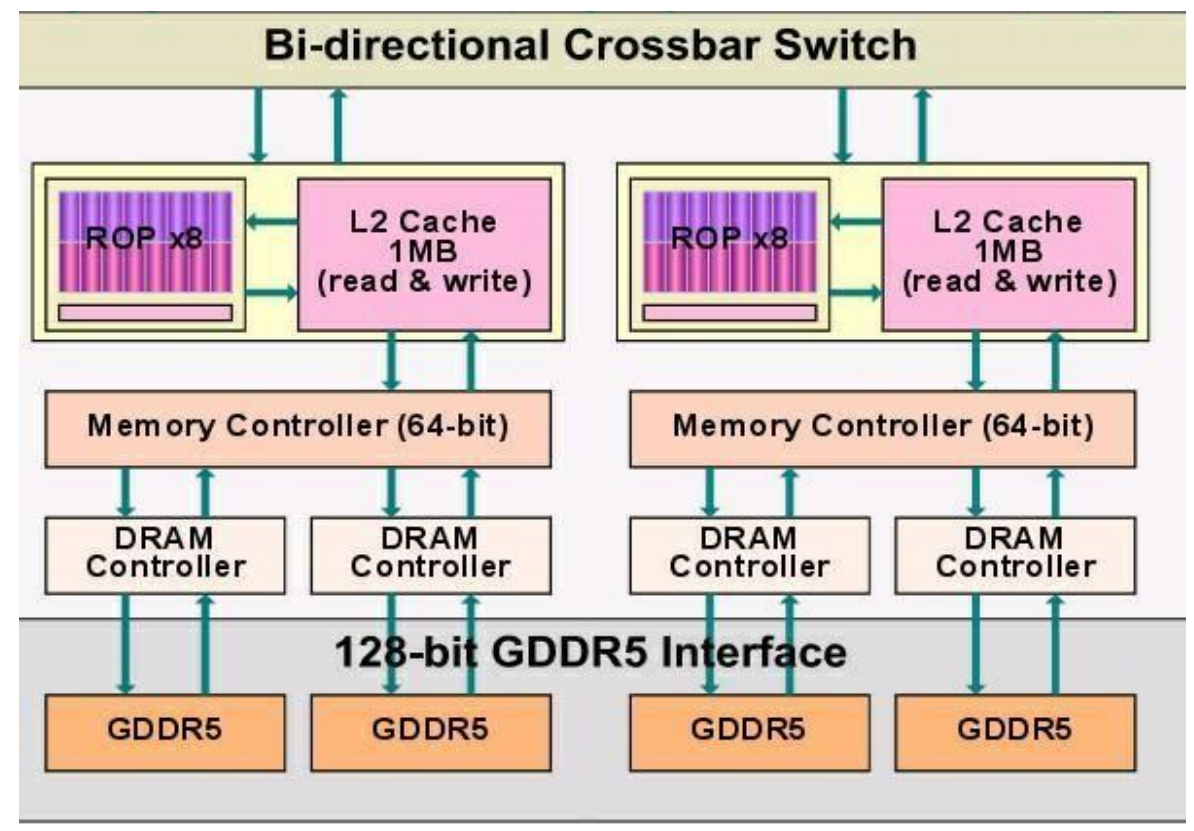

Gambar 2. Hirarki Memori GDDR5

Gambar diatas adalah hirarki memory GDDR5 yang masing-masing memiliki bus memori 64 bit, sebakin besar bus memorinya maka bandwith yang di dapat untuk kartu grafis maka akan semakin besar, oleh karena itulah hal ini juga berpengaruh terhadap performa kartu grafis tersebut.

Dari penjelasan diatas, dapat dirumuskan beberapa permasalahan yaitu sebagai berikut:

1. Apakah merubah nama kartu grafis mejadi produk yang dimaksud akan menaikan performa kartu grafis tersebut?

2. Apakah perubahan nama kartu grafis tersebut akan terbaca dengan akurat oleh software-software pihak ketiga?

3. Seberapa beresiko cara ini dilakukan dan amankah untuk dilakukan?

\section{METODE PENELITIAN}

Banyak penelitian sebelumnya mengenai kartu grafis dan pengembangan aplikasi menggunakan notepad, Dalam upaya pengembangan merubah nama kartu grafis AMD Radeon dengan notepad ini perlu dilakukan studi pustaka sebagai salah satu dari penerapan metode penelitian yang akan dilakukan. Diantaranya adalah mengidentifikasikan kesenjangan (identify gaps), menghindari pembuatan ulang (reinventing the wheel), mengidentifikasikan metode yang pernah dilakukan, meneruskan penelitian sebelumnya, serta mengetahui orang lain yang spesialisasi dan area penelitiannya sama dibidang ini. Beberapa Literature review tersebut adalah sebagai berikut :

1. Penelitian ini dilakukan oleh Vitezslav V. Vicek dari jurnal internasional \& signal pengolahan yang berjudul: "Computation of Inverse Radon Transform on Graphics Cards" Penelitian ini membahas mengenai kartu grafis yang baru diperkenalkan, 
memiliki prosesor kinerja tinggi. Prosesor ini disebut graphics processing unit (GPU), dan dapat memproses banyak data grafis pada satu waktu. Kinerja GPU bisa lebih baik daripada kinerja CPU (unit prosesor sentral) dalam beberapa kasus. Ini adalah alasan mengapa user mencoba untuk menggunakan kartu grafis untuk perhitungan matematika, terutama untuk inverse transformasi Radeon. user memutuskan untuk membuat pelaksanaan GPU disaring dari backprojection karena pelaksanaan GPU menambahkan dua matriks bisa 6 kali lebih cepat dari pelaksanaan CPU. User memiliki dua kemungkinan dasar tentang bagaimana untuk mewujudkan inverse transformasi Radeon. Cara pertama adalah metode langsung: Fourier Iris Teorema, Disaring Backprojection dan Penyaringan setelah Backprojection. Cara kedua adalah dengan algoritma rekonstruksi berdasarkan aljabar linier: Algoritma, berulang Rekonstruksi menggunakan ART. user memilih Disaring Backprojection (FBP) untuk realisasi GPU, karena FBP digunakan di sebagian besar scanner hari ini. User ingin membandingkan waktu komputasi GPU dan CPU Program.

2. Penelitian ini dilakukan oleh L. A. Abbas-Turki dan B. Lapeyre dari Universitas. Paris-Est, Champs-sur-Marne, France yang berjudul: "American Options Pricing on Multi-core Graphic Cards" Penelitian ini membahas mengenai mengeksplorasi penampilan dari Graphics Processing Unit (GPU) di Amerika, masalah pilihan harga menggunakan staf Panjang dan metode Schwartz. eksplorasi ini mencakup studi paralelisasi fase yang berbeda dari pilihan harga di Amerika. mereka juga memberikan perbandingan antara CPU dan GPU dalam harga kontrak satu dimensional. Akhirnya, mereka menyelidiki waktu yang berjalan dari harga kontrak multidimensi. mereka menggunakan NVIDIA Cg Toolkit untuk pemrograman GPU dan perbandingan dengan CPU akan dilakukan terhadap implementasi perpustakaan open-source dari algoritma Longstaff dan Schwartz.

3. Penelitian ini dilakukan oleh D. Stephen Goodrich, Drew D. Granzow, Kevin W. Mundt, Neil L. Condra, Chris F. Felcman, Mark S. Tracy, Sam D. Blackwell, Earl W. Moore dari United States yang berjudul: "Combined Notepad And Notebook Computer" Penelitian ini membahas mengenai Sebuah sistem komputer yang menggabungkan kemampuan kedua notepad dan komputer notebook. Home utama termasuk layar liquid crystal display dengan masukan digitizer untuk digunakan sebagai layar dalam semua mode dan perangkat input bila digunakan dengan stylus dalam mode notepad. Barang yang terletak di home utama adalah floppy disk drive, hard disk drive, unit modem opsional, baterai, dan elektronik dari komputer. home utama berisi sebagian untuk menerima keyboard. ekstensi yang diterima oleh keyboard masih dipertahankan dalam proses selama kondisi penyimpanan dan dalam beberapa kasus penggunaan, di mana tindakan di rumah sebagai dukungan, keyboard parsial untuk memungkinkan memancing dari keyboard. Keyboard dilengkapi dengan kaki sehingga keyboard dapat digunakan jarak jauh dari home utama. home utama berisi sebagian yang dapat beroperasi sebagai komputer yang 
sedang dioperasikan dengan keyboard, sehingga tampilannya benar miring untuk dilihat oleh pengguna. Bagian berputar juga dapat ke posisi umum yang sejajar dengan home utama, tetapi masih memiliki sebagian dan memperpanjang tampilan home untuk bertindak sebagai pegangan.

4. Penelitian ini dilakukan oleh Leroy Bertrand Keely, Jr., Douglas Alan Young, Andrew James Palay dari United States yang berjudul: "Pen-Based Interface For A Notepad Computer" Penelitian ini membahas mengenai sebuah komputer notepad dengan tampilan yang menampilkan sebuah halaman dokumen yang pengguna dapat menulis dengan menggunakan pena atau stylus jenis alat tulis. Terkait dengan halaman adalah sebuah antarmuka yang dapat digunakan dengan pena. Antarmuka termasuk tugas inti berdekatan dengan halaman di mana ikon alat yang sebagian terlihat sampai pena didekatkan salah satu ikon. Ikon alat menjadi sepenuhnya terlihat ketika pena dalam wilayah ikon. Ketika alat diaktifkan dapat pop-up menu, pop-up radial terletak pada tepi dokumen dimana semua pilihan menu yang terletak di setengah lingkaran jauh dari tepi sehingga tangan pengguna sambil memegang pena dan membuat pilihan tidak menghalangi pilihan. Sebuah alat page flipping terletak di sudut halaman dan merupakan dua-stroke pilihan menu yang memungkinkan eksplisit dari halaman berikutnya atau sebelumnya.

\section{HASIL DAN PEMBAHASAN}

Untuk mengatasi berbagai masalah diatas, maka diperlukan sebuah proses dan pengetahuan kusus supaya bisa meluruskan hal-hal yang tidak diinginkan, karena user biasanya sangatlah berharap lebih terhadap apa yang mereka inginkan, berikut adalah jawaban permasalahan dari penelitian ini:

1. Merubah nama kartu grafis ini sebetulnya hanya untuk penyegaran nama perangkatnya saja, umpamanya ada sebuah produk kartu grafis terbaru tetapi kita hanya punya yang produk lama, kita ingin sekali mempunyai produk tersebut dan ingin menikmatinya, disinilah solusinya jika ingin itu terwujud, rubah saja nama kartu grafis yang kita punya menjadi nama produk terbaru tersebut, untuk soal performa tentu saja ini tidak akan meningkat, karena spesifikasi mesin masih tetap sama, dan hanya namanya saja yang berubah, lalu bagaimana solusinya agar performa meningkat? Para user bisa update driver kartu grafisnya ke versi terbaru untuk meningkatkan performa untuk beberapa aplikasi yang di support AMD dan ingin di gunakan, atau bisa juga dengan cara teknik overclocking dengan menggunakan software pihak ketiga untuk mendapatkan performa ekstra.

2. Perubahan nama kartu grafis ini tentu saja akan terbaca dengan akurat di semua sistem dan aplikasi-aplikasi pihak ketiga, karena dalam implementasinya akan meng-assemby ulang dari chipset kartu grafis tersebut, hanya dengan meng-update 
driver terbaru dan memodivikasi package drivernya melalui notepad dan merubah nama kartu grafis yang kita inginkan melalui Device ID perangkat yang kita punya.

3. Teknik rekayasa mengubah nama kartu grafis ini umumnya minim resiko, karena prosesnya yang cukup sederhana dan bisa dilakukan oleh semua kalangan yang memkai produk AMD Radeon, kalaupun memang beresiko masalah yang terjadi hanya peringatan Disable Driver Signature Enforcement atau disebut juga istilah persetujuan izin oleh sistem operasi windows untuk melakukan penginstalan driver agar dapat terpasang driver yang sudah dirubah dengan teknik menggunakan notepad tadi.

\subsection{Implementasi}

Rekayasa teknik merubah nama kartu grafis ini telah di implementasikan oleh penulis sendiri dalam merubah nama kartu grafis ini, Produk yang di gunakan penulis adalah dari vendor HIS (Hightech Information System) AMD Radeon R7 265 ipower Iceq X2.

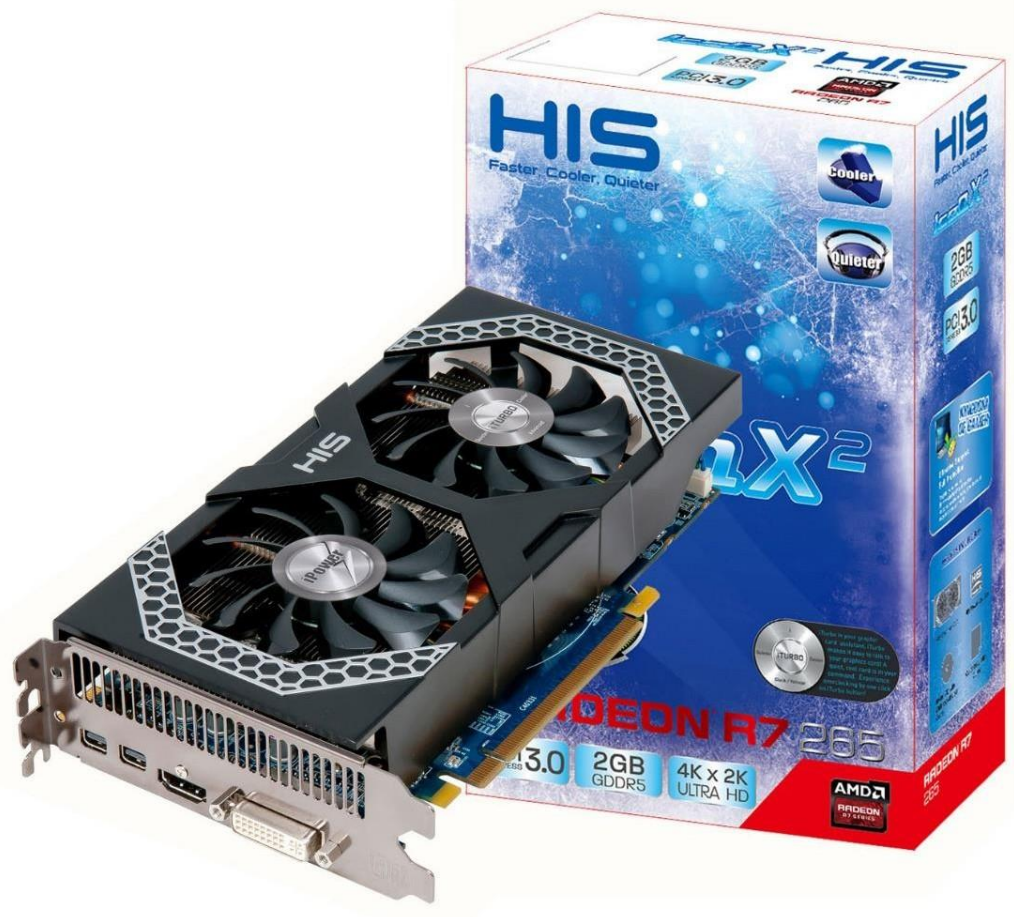

Gambar 3. HIS R7 265 ipower Iceq X2

(Sumber : google.com)

HIS adalah merek yang diakui dunia internasional dari kartu grafis. Dari waktu ke waktu, HIS dibandingkan dan diuji oleh ratusan reviewer dunia terkenal. Hasilnya fenomena, HIS telah terbukti menawarkan kartu grafis yang jauh lebih unggul, lebih dingin, lebih hening, dan lebih cepat daripada kartu grafis merk terkemuka lainnya. 
Hingga kuartal I 2015, HIS telah memenangkan lebih dari 1700 penghargaan AMD dengan solusi kartu grafis dari media utama di seluruh dunia. HIS sedang diakui dengan memberikan kinerja terkemuka dan pemenang penghargaan produk: IceQ, IceQ $\mathrm{X}$, IceQX2, IceQX2II, OC dan Turbo Edition.

HIS didirikan pada tahun 1987 dengan misi untuk menghasilkan produk-produk PC berkualitas tertinggi dalam industri. Berkantor pusat di Hong Kong, dan dengan kantor-kantor penjualan dan jaringan distribusi di Eropa, Timur Tengah, Amerika Utara dan Selatan, Asia Pasifik, manfaat pelanggan di seluruh dunia dari pelayanan yang efisien dan lokal. fasilitas manufaktur HIS di Cina dikelola oleh tim profesional dengan keahlian dalam kontrol kualitas dan perencanaan produksi. Bekerja dengan klien kelas dunia, HIS telah secara konsisten memenuhi standar kualitas tinggi dan volume pesanan terpenuhi dalam waktu singkat.

HIS bangga menjadi partner AMD Resmi 1 Tier AIB Mitra, Certified Partner dan Launching Mitra. Untuk hubungan jangka panjang dan hubungan yang menguntungkan dengan AMD, memungkinkan HIS untuk bekerja sama dengan AMD untuk mempromosikan kartu grafis AMD dan berusaha untuk memberi nilai terbaik pada pemasaran dan penjualan produk AMD.

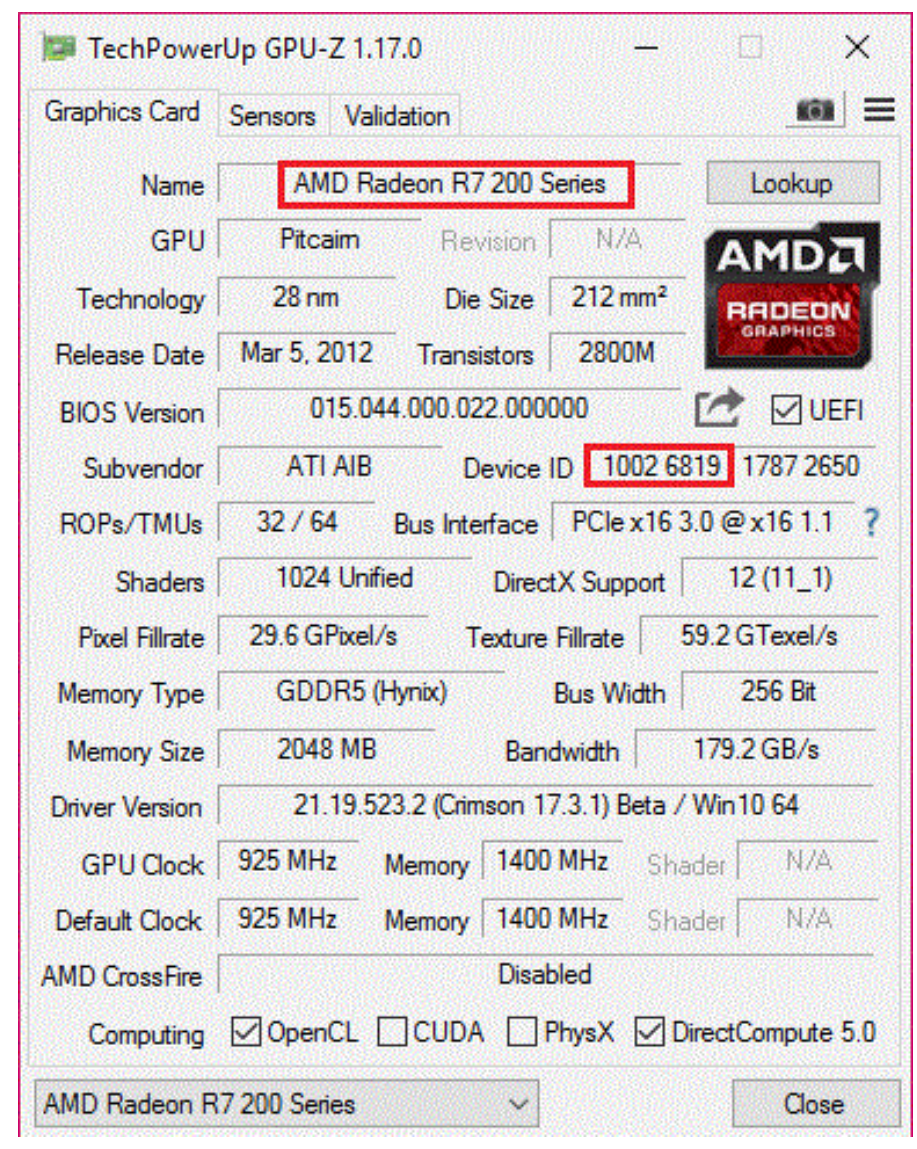

Gambar 5. Spesifikasi HIS AMD Radeon R7 265

8| Ary, Khalid-Rekayasa Teknik Merubah Nama Kartu Grafis ... 
Gambar diatas adalah aplikasi GPU-Z, dimana aplikasi ini dapat di gunakan untuk memperoleh infomasi mengenai kartu grafis secara lengkap, HIS R7 265 ipower Iceq X2 yang terbaca oleh GPU-Z ini adalah AMD Radeon R7 200 Series dimana nama dari kartu grafis ini tidak sesuai dengan nama aslinya, di karenakan penamaan 200 series sangatlah umum, sehingga sistem tidak akurat membaca sebuah informasi kartu grafis tersebut. Di dalam GPU-Z ini terdapat Device ID 10026819 yang diberi tanda merah, dimana Device ID inilah yang akan kita gunakan untuk mencari ID dari kartu grafis ini pada Setup Information Driver menggunakan notepad.

Pada penulisan ini penulis ingin merubah nama kartu grafis tersebut sesuai dengan nama originalnya yaitu AMD Radeon $R 7$ 265, karena nama original ini adalah hasil dari perubahan rekayasa teknik menggunakan notepad di windows 10 sehingga nama kartu grafis ini dapat digunakan sebagai acuan untuk mengetahui nama produk yang sebenarnya, lihat Gambar 6.

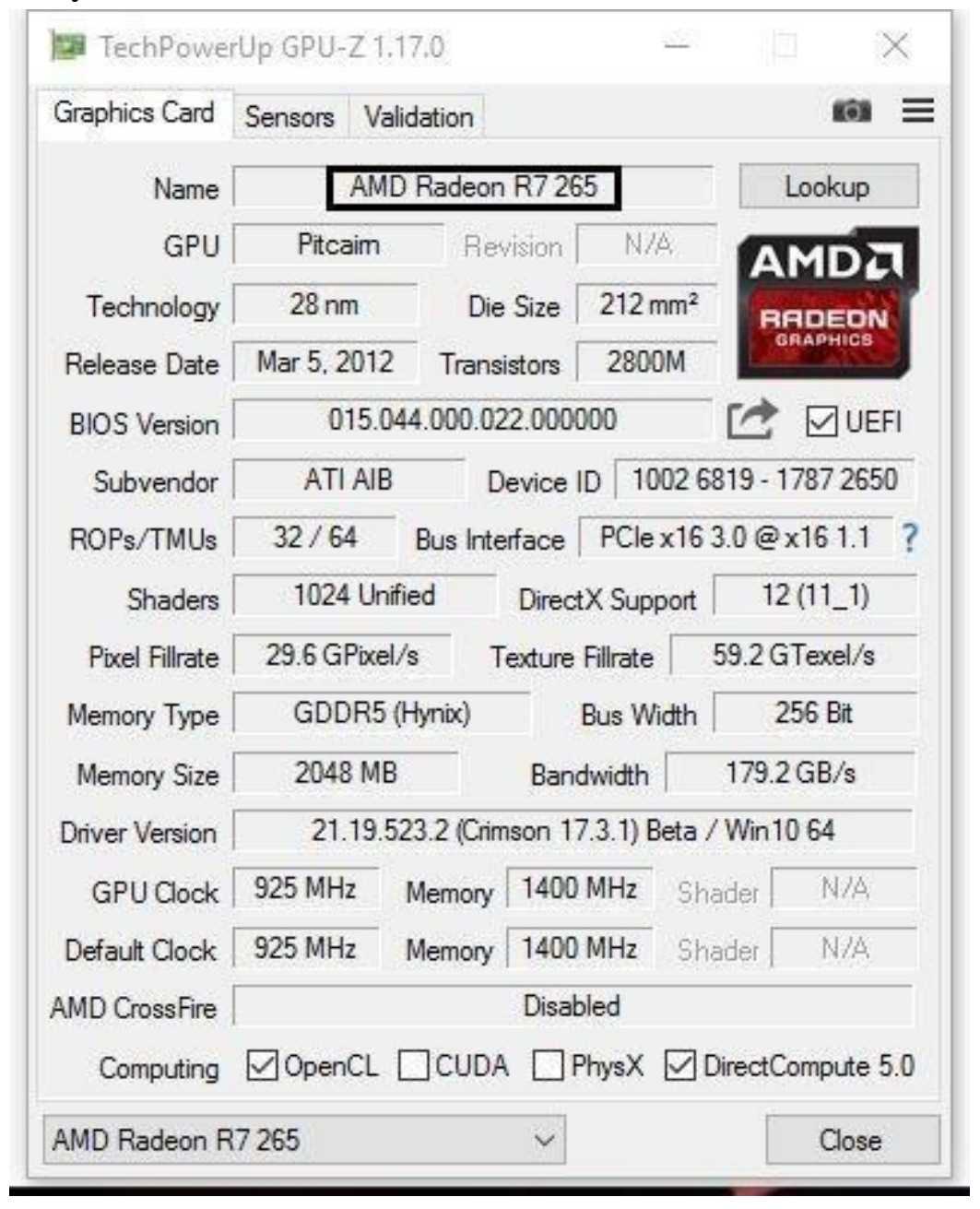

Gambar 6. Nama Kartu Grafis Yang Seharusnya 
Pada gambar diatas adalah gambaran hasil kartu grafis yang seharusnya, yaitu bernama $A M D$ Radeon $R 7265$ dan sekaligus ingin penulis lakukan untuk implementasinya, pada proses ini perlu tahapan-tahapan yang penting dan harus dilakukan agar tercapainya suatu tujuan untuk penelitian ini, berikut tahapan yang perlu dilakukan agar dapat terwujudnya merubah nama kartu grafis HIS AMD Radeon $R 7$ 265:
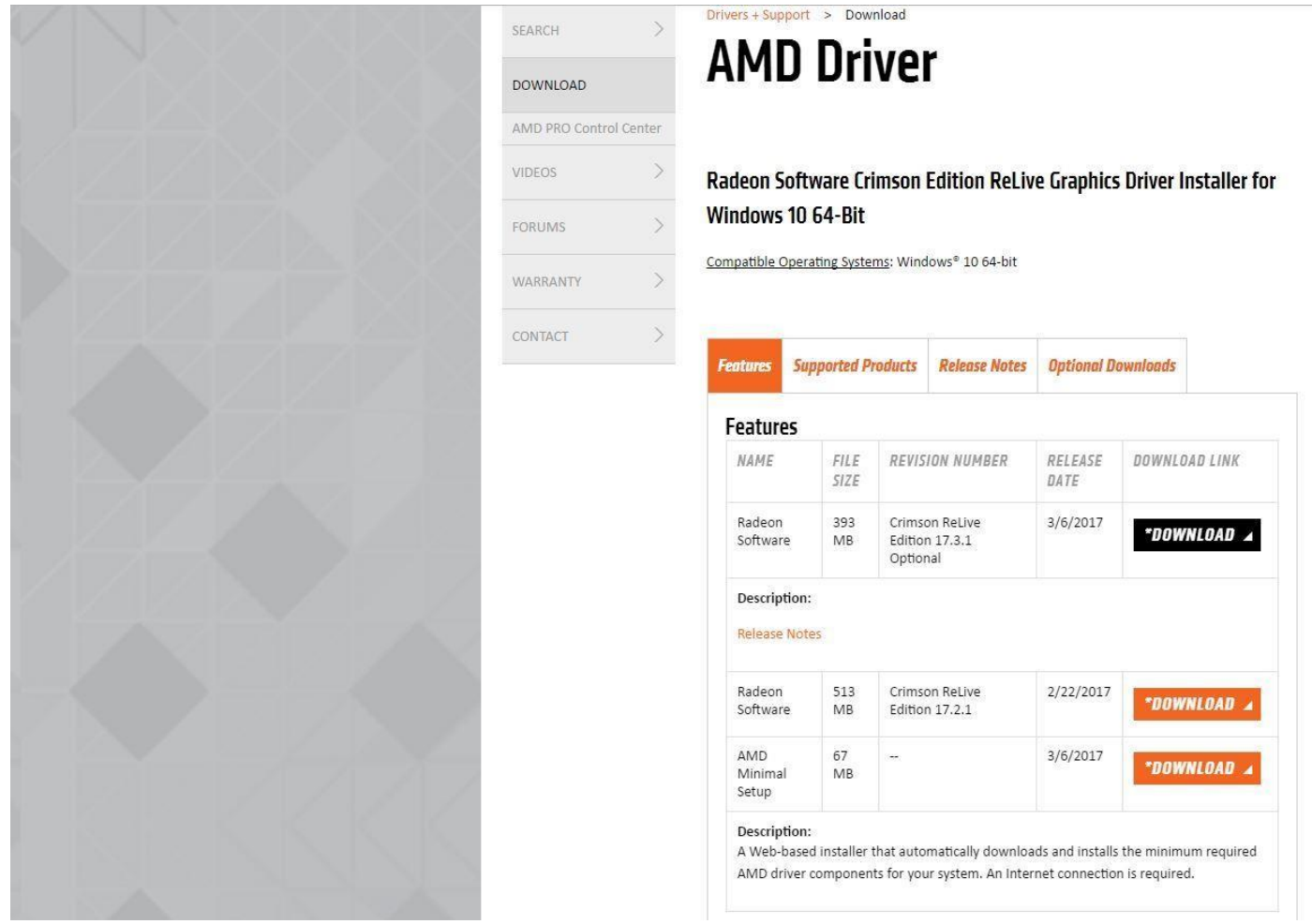

Gambar 7. Website Resmi Untuk AMD Driver

Sebelum melakukan tahapan user perlu meng-update driver kartu grafisnya terlebih dahulu melalui website resmi AMD, Pada website AMD kita dapat untuk mendownload driver terbaru agar mempermudah proses mengubah nama kartu grafis tersebut, disana dapat mencari nama kartu grafisnya secara manual dan sesuai dengan produk yang kita punya agar cocok dan sesuai dengan driver yang akan dipasang, setelah selesai mendownload buka setup.exe dan men extract package-nya, setelah selesai mengharuskan kita untuk meng cancel penginstalan. Karena driver tersebut akan tersimpan di Local C windows. 


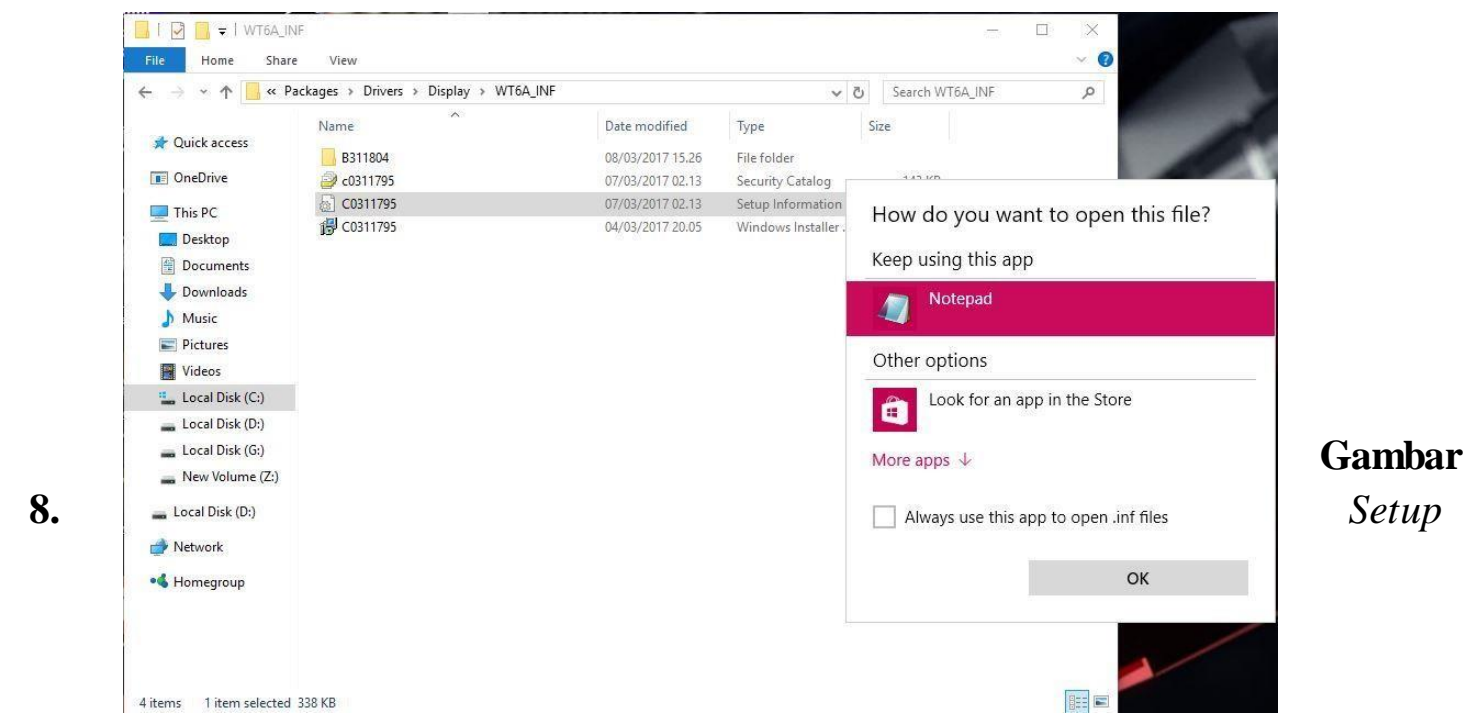

Information

Dari hasil download driver terbaru tadi, user dapat mengunjungi local $C-A M D$ Packages-Drivers-Display-WT64_INF dan membuka file Setup Information menggunakan Notepad, tujuanya untuk mengubah nama kartu grafis AMD Radeon R7 200 series dari Device ID tersebut.

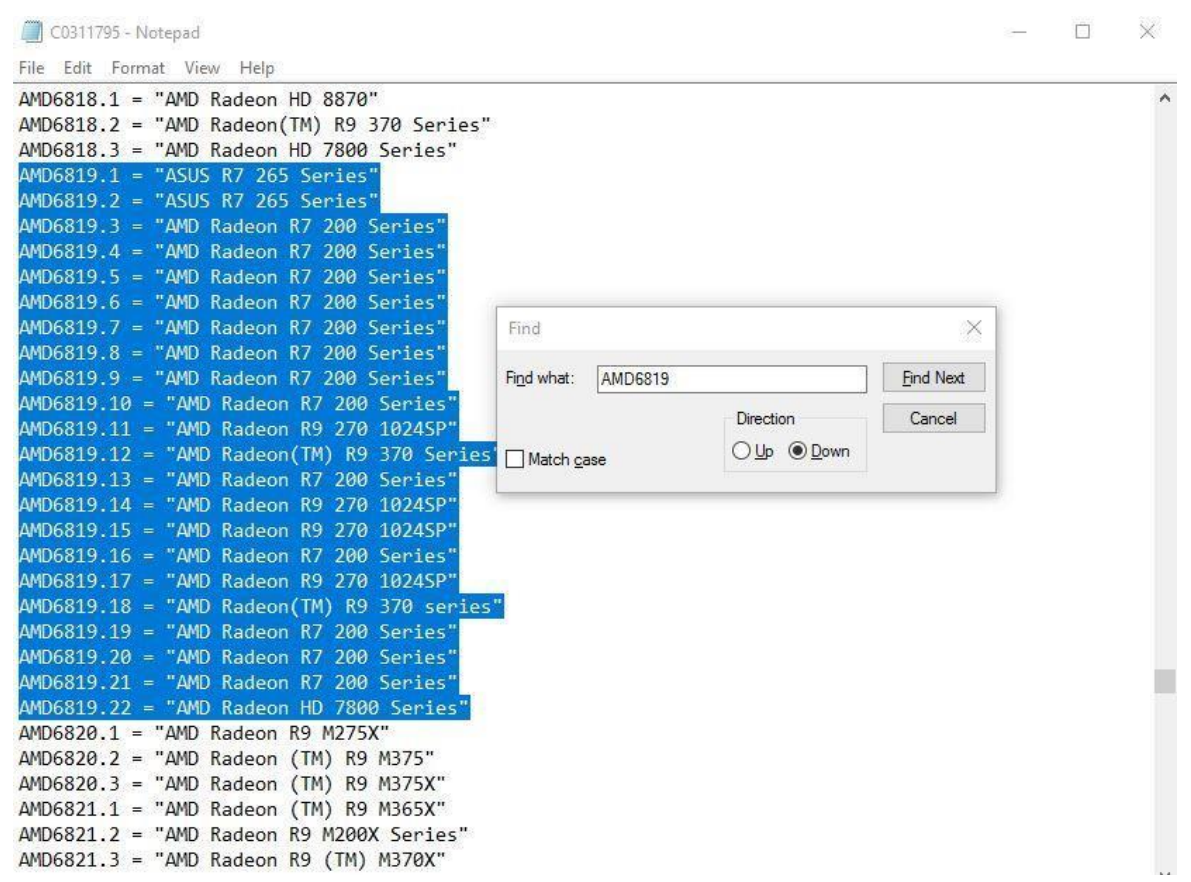

Gambar 9. Mengubah Nama Kartu Grafis Menggunakan Notepad

Untuk bisa menemukan Device ID dari kartu grafis yang kita punya, user bisa menggunakan fitur search dan memasukan Device ID-nya, Device ID dari HIS AMD 
Radeon R7 265 adalah AMD6819 yang sudah diberi tanda merah pada GPU-Z diatas (Gambar 5), maka kita akan menemukan nama produk tersebut, nama default dari driver ini adalah AMD Radeon $R 7200$ Series maka penulis akan merubah nama kartu grafis tersebut menjadi AMD Radeon R7 265.

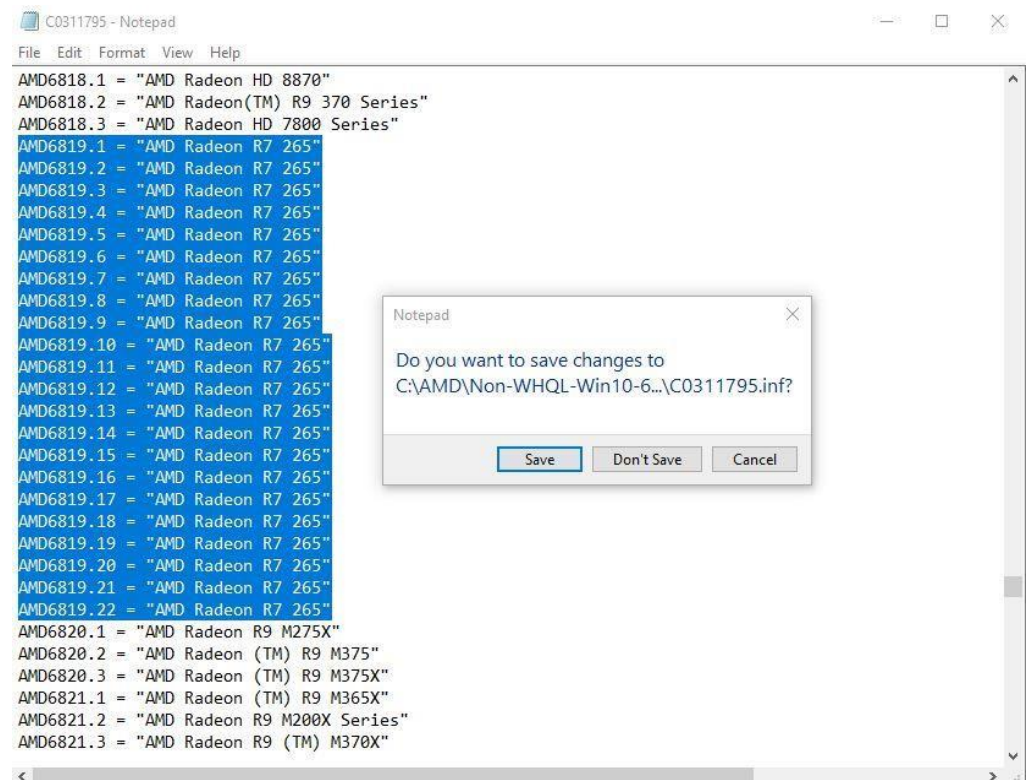

Gambar 10. Nama Kartu Grafis Yang Sudah Dirubah Dengan Notepad

Setelah selesai merubah nama kartu grafis HIS AMD Radeon R7 265, User dapat menyimpannya ke folder semula, setelah itu melakukan step men-Disable Driver Signature Enforcement di windows 10, User bisa mengunjungi startup menu, kunjungi All Settings-Update \& Security-Recovery-di menu Advanced Startup, Restart NowTroubleshoot-Advanced Option-Startup Settings-Restart-klik angka 7 di keyboard (Disable Driver Signature Enforcement). lalu sistem akan me-restart secara otomatis.

\section{Startup Settings}

Press a number to choose from the options below:

Use number keys or functions keys F1-F9.

1) Enable debugging

2) Enable boot logging

3) Enable low-resolution video

4) Enable Safe Mode

5) Enable Safe Mode with Networking

6) Enable Safe Mode with Command Prompt

7) Disable driver signature enforcement

8) Disable early launch anti-malware protection

9) Disable automatic restart after failure

Gambar 11. Startup Settings windows 10 (Disable Driver Signature Enforcement) 
Setelah sistem me-restart kemudian kita dapat meng-instal Driver yang sudah di modifikasi tersebut di Local C-AMD-Setup.exe-Express Instal.

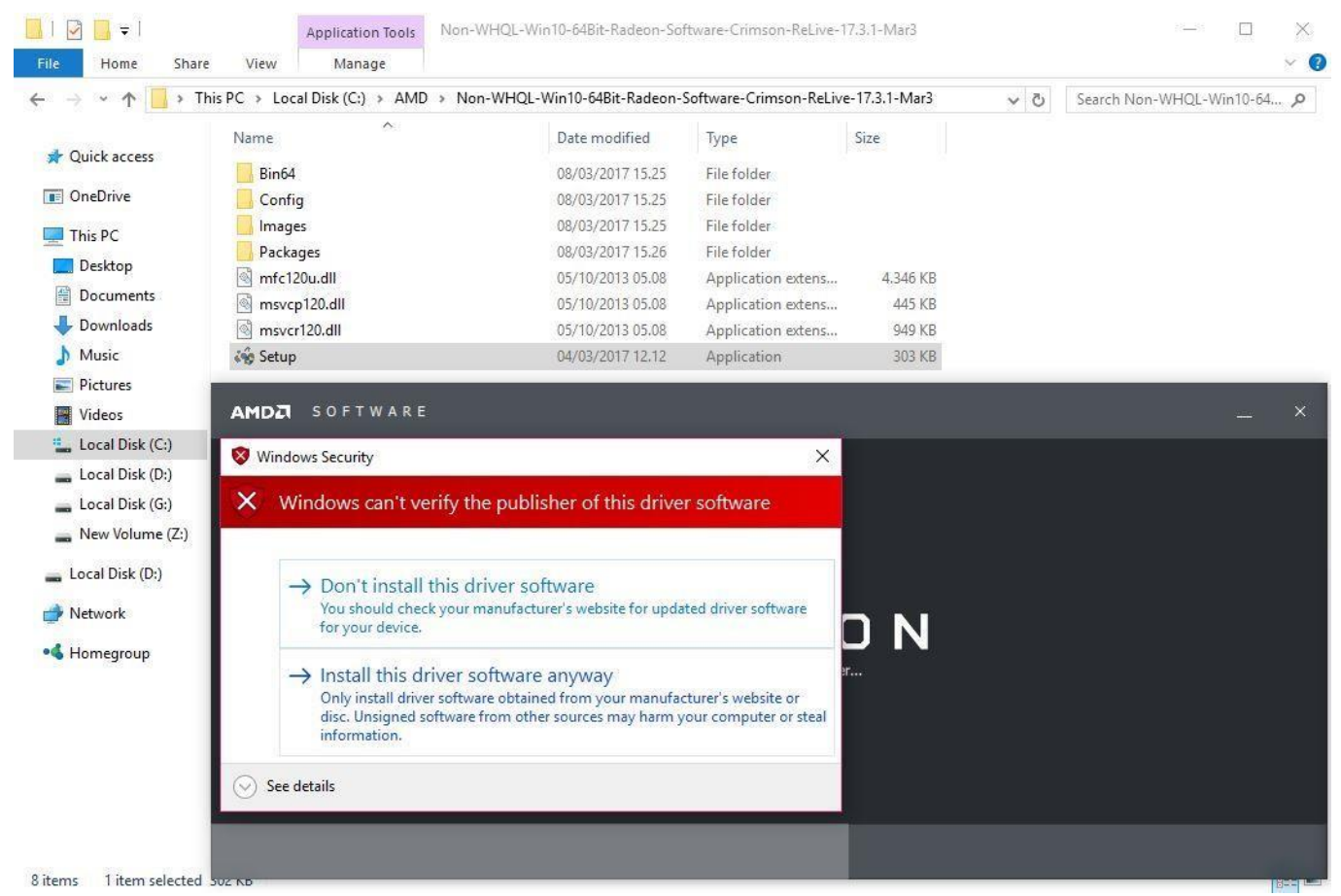

Gambar 12. Windows Security

Pada tampilan windows security yang muncul merupakan hasil dari menonaktifkan Disable Driver Signature Enforcement, karena sistem akan membutuhkan verifikasi pada tanda tangan digital (signature) driver. Pada versi windows terbaru seperti windows 8 dan windows 10 mempunyai sebuah fitur untuk mengecek signature pada suatu driver yang terpasang pada laptop maupun PC dekstop. Dengan fitur tersebut kita dapat mengetahui apakah driver kita sudah mendapat persutujuan dari microsoft yang berupa tanda tangan digital (signature) atau belum. Jika pada saat user menginstal driver dan driver tersebut tidak memiliki signature (unsigned drivers) dari microsoft, biasanya windows akan memblokir instalasi tersebut. Setelah penginstalan selesai maka akan diminta untuk merestart sistem. 


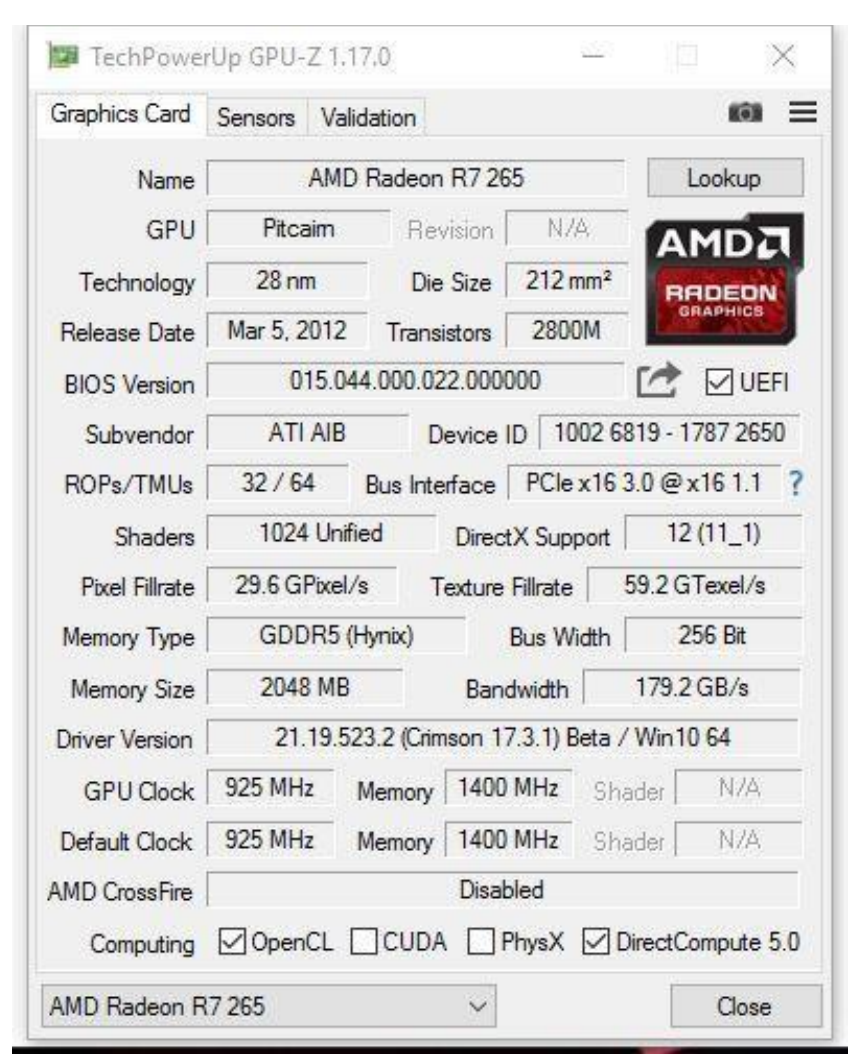

Gambar 13. Hasil Spesifikasi HIS AMD Radeon R7 265

Pada gambar diatas adalah dari hasil aplikasi GPU-Z pada perubahan nama kartu grafis HIS AMD Radeon R7 265, yang nama sebelumnya adalah AMD Radeon R7 200 Series telah berubah menjadi AMD Radeon R7 265 dan nama dari kartu grafis ini sudah sesuai dengan nama produk originalnya.

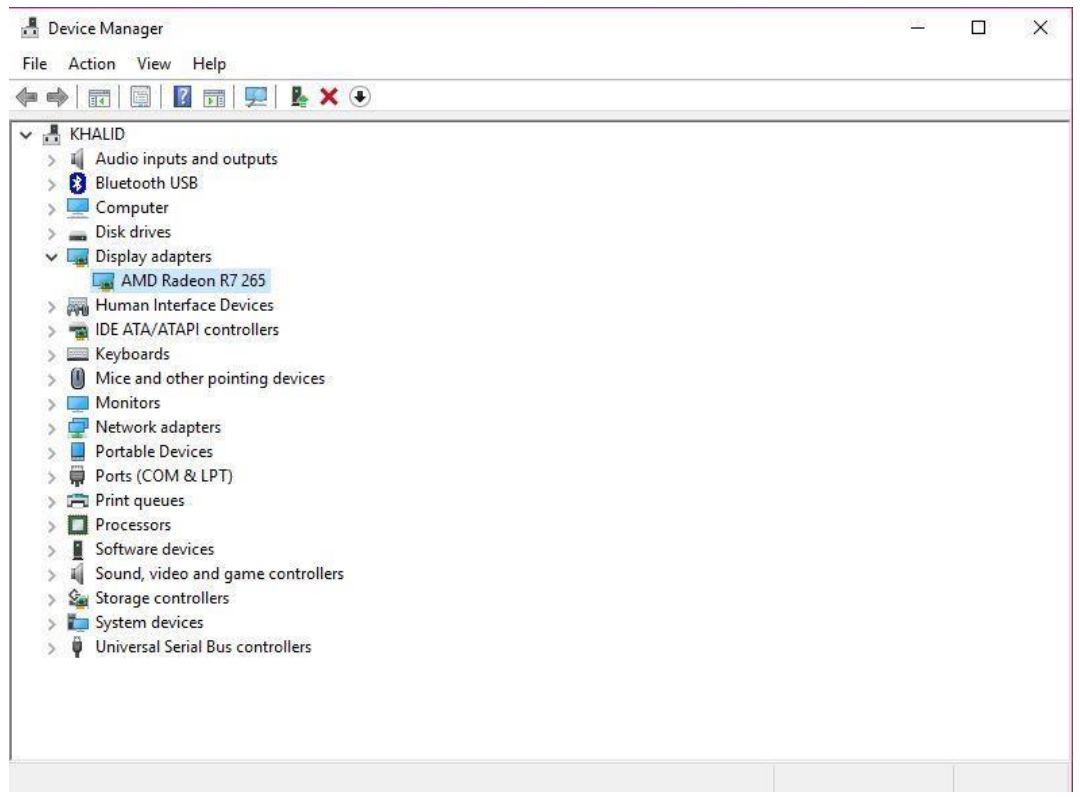

Gambar 14. Hasil Akhir Yang Terbaca Oleh Divice Manager Windows 10 14 | Ary, Khalid-Rekayasa Teknik Merubah Nama Kartu Grafis ... 
Hasil perubahan nama pada device manager adalah yang paling tepat, karena device manager akan membaca perangkat hardware melalui chipset dan bios komponen pada sistem hardware, dengan ini implementasi untuk merubah nama Kartu Grafis AMD Radeon dengan menggunakan notepad sudah berhasil.

\section{KESIMPULAN}

Berdasarkan uraian diatas, dapat disimpulkan bahwa merubah nama kartu grafis AMD Radeon kususnya dari brand terkenal HIS R7 265 dapat dengan mudah untuk di implementasikan, nama default sebelumnya dari kartu grafis ini adalah AMD Radeon $R 7$ 200 Series menjadi AMD Radeon $R 7$ 265, Hal ini karena penulis telah menguji perangkatnya secara langsung yang dapat memudahkan untuk implementasinya, pengujiannya yang dapat di buktikan dengan menggunakan software pihak ketiga yang bernama GPU-Z.

\section{SARAN}

Menggunakan tool GPU-Z tentu bisa menjadi acuan untuk melihat spesifikasi secara lengkap dan banyak sekali di gunakan oleh pengguna hardware, dengan begitu perubahan nama kartu grafis ini akan terbaca akurat oleh software pihak ketiga manapun, terlebih lagi perubahan nama AMD Radeon R7 265 ini juga telah terbaca dengan akurat pada device manager bawaan windows 10 , karena perubahan nama kartu grafis yang dilakukan lewat notepad tadi cukup banyak.

\section{DAFTAR PUSTAKA}

[1] Vitezslav V. Vicek, 2004, Computation of Inverse Radon Transform on Graphics Cards. International Journal Of Signal Processing.,

[2] L. A. Abbas-Turki dan B. Lapeyre dari Universitas. Paris-Est, Champs-surMarne, France 2009, American Options Pricing on Multi-core Graphic Cards, Appl. Probability Res. Group, University. Paris-Est, Champs-sur-Marne, France.

[3] D. Stephen Goodrich, Drew D. Granzow, Kevin W. Mundt, Neil L. Condra, Chris F. Felcman, Mark S. Tracy, Sam D. Blackwell, Earl W. Moore 1994, Combined Notepad And Notebook Computer, Compaq Computer Corporation. United States

[4] Leroy Bertrand Keely, Jr., Douglas Alan Young, Andrew James Palay, 2002, Pen-Based Interface For A Notepad Computer, Microsoft Corporation, United States

[5] FLaguy954, 2014, The R7 265 is a Radeon 7850 with MANTLE, any chance we'll be able to unlock it to a 7870 (or $R 9$ 270) when it releases, http://www.overclock.net/t/1466826, diakses tanggal 09 Mei 2017. 
[6] Audentio Design, 2016, quantum break more like quantum broken, https://forums.anandtech.com/threads/ 2469338, diakses tanggal 09 Mei 2017

[7] HIS Digital, 2008, HIS R7 265 iPower IceQ X² Boost Clock 2GB GDDR5,

http:/www.hisdigital.com/ca/product2-849.shtml, diakses tanggal 09 Mei 2017 